\title{
Lapurdum
}

Euskal ikerketen aldizkaria | Revue d'études basques |

Revista de estudios vascos | Basque studies review

$3 \mid 1998$

Numéro III

\section{A la mémoire de Georges Viers.}

\section{Pierre Barrère}

\section{OpenEdition \\ Journals}

\section{Édition électronique}

URL : https://journals.openedition.org/lapurdum/1760

ISSN : 1965-0655

Éditeur

IKER

Édition imprimée

Date de publication : 1 octobre 1998

Pagination : 334-337

ISBN : 2-84127-152-8

ISSN : $1273-3830$

Référence électronique

Pierre Barrère, «A la mémoire de Georges Viers. », Lapurdum [En ligne], 3 | 1998, mis en ligne le 01 septembre 2010, consulté le 24 février 2022. URL : http://journals.openedition.org/lapurdum/1760 


\section{A la mémoire de Georges Viers.}

Début 1998, s'éteignait à Espelette le professeur Georges Viers, géographe et humaniste pour qui le Pays basque a été un champ d'études privilégié. Sa thèse, Pays basque français et Barétous. Le relief des Pyrénées orientales et de leur Piémont, publiée en 1960 chez Privat, constitue un formidable monument à la connaissance qui fait date à l'instar par exemple de la thèse de Th. Lefebvre en 1933. Georges Viers n'hésita pas non plus à venir épauler le début des études universitaires en domaine basque à la Faculté à Bayonne en y donnant ses cours de géographie. Mais pour lui rendre ici hommage, nous préférons présenter le discours que fit le vendredi 16 janvier 1998, lors des obsèques de Georges Viers à Espelette, son collègue et ami Pierre Barrère, professeur émérite de l'Université de Bordeaux III, que nous remercions de nous avoir permis de reprendre le texte.

La rédaction

\section{Souvenir de Georges Viers}

Pour avoir été un ami de longue date et un compagnon de travail privilégié de Georges Viers, je voudrais dire tout ce que nous venons de perdre par sa mort, mais aussi la leçon qu'il nous laisse.

Il aimait évoquer son enfance à Montrouge et dire sa fierté, issu d'une famille modeste et rigoureuse à la fois, d'avoir pu, par l'intelligence et le travail, accomplir une remarquable ascension sociale. L'Ecole Normale en fait un instituteur révélant très vite des dons pédagogiques remarquables. C'est aussi le moment où il conforte ses engagements politiques et sociaux dont la réussite ne l'écartera pas. Il restera fidèle à ses opinions comme il a toujours été fidèle à ses amitiés.

Confronté très tôt à la maladie, il en surmonte les effets avec un grand courage. A la recherche d'une vie saine, il multiplie les contacts avec la nature. Véritable apôtre de la marche, il devient à l'occasion de multiples randonnées un botaniste averti, géologue et botaniste à la fois, capable de se mesurer aux meilleurs spécialistes. Climatologue de talent, observateur bénévole, obstiné et minutieux, ses relevés météorologistes furent très appréciés et utilisés par les services régionaux compétents.

Il décida un jour de quitter les brumes de la capitale pour un village basque : Saint-Étienne de Baïgorry. Des générations d'enfants y profitèrent de sa pédagogie active, où les leçons formelles étaient enrichies par l'étude du milieu que maîtres et élèves observent de conserve. Ce transfert en Pays Basque va orienter de façon décisive et heureuse tout le reste de sa vie.

C'est là qu'à l'occasion d'un voyage d'études, les géographes de l'Université de Bordeaux découvrent cet «instit» autodidacte et percutant dont ils estiment vite la valeur et l'encouragent à venir à la Faculté. Il y acquiert dans le minimum de temps les grades universitaires, sans cesser toutes ses autres activités, preuve nouvelle de son courage. Une brillante réussite à l'Agrégation oriente définitivement sa carrière vers l'Enseignement supérieur, et c'est tout naturellement au Pays Basque qu'il trouve les sources de ses recherches. 
La préparation de ses thèses sur le relief du Pays Basque et du Barétous et sur la ville de Mauléon lui permet d'approfondir encore sa prise de conscience des caractères si particuliers d'un pays qu'il aime déjà, où sa famille se développe et où sa vie professionnelle et affective sont en symbiose totale.

Il traduira cela par un bel ouvrage en 1975 sur le Pays Basque, par de nombreux articles scientifiques sur la région et plus tard par sa collaboration à la belle plaquette de 1995 sur Espelette. Il y note avec émotion la capacité d'accueil et l'aptitude à l'évolution d'un village où il a déjà «planté » sa demeure de retraite. Nommé professeur de géographie à l'Université de Toulouse, il voit s'épanouir sa vie professionnelle. Sur la base d'un enseignement fait de richesse documentaire, de réflexion profonde et de rigueur d'exposition, il sera pour les étudiants un maître à penser. Original sans rechercher le paradoxe, son bon sens sera aussi très apprécié dans sa participation aux jurys des grands concours de recrutement.

Parallèlement il sera un des géographes les plus productifs de cette période. Je ne citerai que les cinq manuels de morphologie, de climatologie, de géographie zonale des régions froides et tempérées, de géographie des forêts, et son importante contribution au Dictionnaire de Géographie, tous ouvrages qui trente ans après sont encore des bases très appréciées.

Il n'a pas pour autant cessé d'être un homme de terrain, un des plus grands voyageurs parmi les géographes français. Il n'y a pas de région française et de pays européens qu'il n'ait parcourus, souvent plusieurs fois, en camping familial, en immersion totale dans les sociétés. Il gardait au fil des ans une curiosité intacte, et s'attachait à saisir toutes les nuances de la condition humaine, alimentant aux sources mêmes sa réflexion politique et délivrant aux étudiants les données prises sur le vif. Photographe dans l'âme, les riches collections de diapositives qu'il a rapportées et publiées sont encore un élément précieux de pédagogie active.

Ces actions variées lui ont valu la considération des étudiants qui en portent encore témoignage et l'estime et le respect de ses pairs. Il y eut bien quelques dissonances dans l'effervescence de 1968, quand il s'appliqua à éviter les dérives dont l'Unité d'Enseignement dont il avait la charge aurait pu souffrir. Il ne garda pas d'amertume à l'égard de ceux qui lui reprochèrent alors de se conduire en sage.

Très ferme dans son langage, il était cependant sans outrance et évitait les conflits. Pour avoir beaucoup changé de résidence, il n'a jamais eu de réaction de déraciné. Il s'intégra toujours aux environnements humains si divers qu'il rencontra, sans doute parce qu'il n'avait pas transporté de lieu en lieu un quelconque chauvinisme régional. Il disait souvent, en forme de boutade : « Nous sommes tous des métis »; non pas au sens ethnique, mais il exprimait la richesse des échanges qu'il sut partout provoquer. Y eut-il maison plus naturellement accueillante que celle de Jo et d'Anne-Marie ? Certainement pas.

Le choix d'Espelette pour une retraite qui malheureusement s'achève trop tôt est symbolique de cet enracinement toujours renouvelé. Sur la frange de ces montagnes avec lesquelles il avait maintenant cinquante ans d'intimité, il sut se faire admettre, put faire entendre sa voix sur les réalités locales, faire avancer la connaissance, et jouer un rôle important dans la vie associative. Mais ce ne fut pas qu'une retraite à la Candide bien que, comme dans toutes ses demeures antérieures, il ait porté, tant que ses forces le lui ont permis, un soin méticuleux à son très beau jardin. 
Mais malgré les rudes atteintes de l'âge et de la maladie il n'a jamais suspendu son travail et sa réflexion sur le monde et la condition humaine. Surtout, il a continué à faire profiter les autres de sa sagesse.

C'est, à travers l'image de l'ami très cher, l'image du sage qu'il nous faut conserver. Plutôt qu'esquisser un portrait maladroit, je préfère vous livrer un texte d'un philosophe chinois ${ }^{1}$, qui ne me paraît pas du tout être impie en ce lieu, et qui me semble s'appliquer parfaitement à ce que fut Jo et à la façon dont nous devons maintenant continuer à songer à lui : Le sage diffère des autres hommes parce qu'il conserve les vertus que la nature a mises en son cour. Il conserve en son cour la bienveillance et l'urbanité. Un homme bienveillant aime les autres; un homme poli respecte les autres.

Celui qui aime les autres en est toujours aimé ;

Celui qui respecte les autres en est toujours respecté.

\section{PierRe BARRÈRE}

A Espelette le vendredi 16 janvier 1998

\footnotetext{
${ }^{1}$ Meng-T'seu, disciple de Confucius.
} 